\title{
A Different approach to socio-economic statistics compared to the classical statistics approach
}

\section{A different approach to socio-economic Statistics compared to the approach of Classical Statistics}

Measurements in biology belong to biometrics and to biostatistics. The readers of this journal may not be aware, however, that the original and legitimate use of "statistics" only applied to the economic and social sciences. It was used to report in an official publication the noteworthy events and remarkable features of the public administration of the state, as state-istics. It also may come as a surprise to discover that those early "statistical yearbooks" had no tabulations and hardly contained any numbers ${ }^{1}$. The invitation to contribute some thoughts on statistics to the International Journal of Biometrics and Biostatistics came as a complete surprise as I am neither a biologist nor a biometrician. It may be justified though, as I was occasionally the statistical consultant working with medical researchers and psychologists, during my half century of teaching statistics in business schools and departments of economics.

I should also mention my biomedical involvement when I participated as a volunteer in a study to determine the effects of Vitamin B on aging. At the age of 90, I wanted to experience being a test subject instead of the statistical consultant. I warned the project leader, as a retired professor of statistics, that their results of measuring vitamin $\mathrm{B}$ in persons of different ages at the same point in time was not the equivalent nor a valid substitute for measuring that effect on the same persons recorded at successive stages during their aging. In other words, doing this research e.g. in 2014 on six men: one 40 years old, another 50 years old, another, 60 years old, etc. answers a different question than when each one of these six persons were tested during successive stages of their aging; when each was tested when he was 40, then tested again 10 years later at age 50, then again at age 60 , etc. until his $90^{\text {th }}$ birthday. The practical difficulties of that kind of research could be insurmountable. Even if it could be done, the results would be influenced by numerous changes in the surrounding circumstances such as the general nutritional culture in addition to the observed changes due to the nutritional effect of vitamin B. That was bad news regardless of how painstaking that empirical research was done.

Another experience happened at the end of my first year teaching Statistics at the Facultad Economia (Economics Department) of the Universidad Central de Venezuela in Caracas. To better cope with the Spanish language and the appropriate statistical terminology I used the Spanish translation of Udny Yule's standard work on statistics as the textbook. It reflected the British evolution of statistics, dealing mostly with measurements in the bio sciences, written for natural scientists. This happened in 1949 at the beginning of my teaching when I took for granted that there was just one theory of statistics that applied equally to all fields, a belief still shared by many statisticians. I was younger than most of my 30 students who were employees at the Banco Central whose vice president also was the dean of that "How Economic and Social Statistics became the Stepchildren of the Profession" O. Winkler, paper presented at the JASA meeting in Sn. Diego, CA. JSMA 2012, Section on Statistical Education, pp 2663 -2669, Request your copy.

\author{
Volume 7 Issue I - 2018 \\ Othmar WWinkler \\ McDonough School of Business, Georgetown University, USA
}

Correspondence: Othmar WWinkler, Professor emeritus, McDonough School of Business, Georgetown University, USA, Email winklero@georgetown.edu

Received: December 20, 2017 | Published: January 08, 2018

economics department. At the end of the semester the leader of these students challenged me in class: "Professor, I have to tell you, that the statistical methods you have taught us cannot be applied to our work in the Banco Central! " That bold and embarrassing confession was a first jolt to my belief that the theory of statistics applies equally to all data.

During the following decades of teaching in economic departments and business schools, I had opportunities to teach in other areas such as Georgetown University's Psychology Department, the School of Languages and Linguistics and the Medical School. More important for the evolution of my thinking was my participation in various applied statistical studies to solve marketing problems, linguistic research, and be in charge of statistics supporting large class-action lawsuits to prove that various departments of the Federal Government actually discriminated against its women employees. These studies not only gave me access to very reliable, seldom accessible confidential data but also presented unique situations that called for rethinking the interpretation of statistical results. During those years I eventually became convinced that there actually exist different kinds of statistical data that require different methods.

At the yearly meetings of American Statistical Association in 1984 I presented a paper critical of government economic forecasts. The European publisher Marcel Dekker had a professor from a southern university acting as a "scout" in that meeting. That scout approached me afterwards to arrange a meeting with Dr. Maurice Dekker, the chairman of that publisher. That meeting ended with a contract to write a manuscript that, in their words "would break with the tradition of writing textbooks in socio-economic statistics." A year later I submitted the finished draft of "A Foundation of Descriptive Statistics in the Social Sciences." The verdict of that publisher's reviewers: "Do not publish this manuscript under any circumstances - that book would be an embarrassment for publisher and author." These reviewers, obviously mathematical statisticians, not finding what they expected, strongly disapproved of what they considered heresy. Such can be the fate of innovation in academia.

Experts often obstruct innovation. They can delay it but ultimately cannot keep it from breaking through. Two decades later, in 2007, a German publisher surprised me with his request: "would I be willing to write a book for Springer's statistical series?" "No," I objected, "you are a mathematical publishing house. What I have to say is about 
socio-economic statistics, but it is not mathematical, not the usual probability-based confirmatory kind of statistics." But Dr. Thomas, Springer's agent, insisted: "that is exactly what we are looking for, a non-mathematical book on economic and social statistics." In 2009, the manuscript, printed in India, became available, both in hard-cover in the Springer series of statistics books and in electronic form as "Interpreting Economic and Social Data-A Foundation of Descriptive Statistics" $2 "$

Allow me to give a simple graphical demonstration to show how socio-economic statistical data differ from measurements in biology. The picture - on the next page - is a composite of many small rectangular pictures. None of them is of particular importance or interest. Together, though, they form another, large picture that is different from those many small pictures that compose it, like colored stones composing a mosaic. That joint picture is not very sharp, yet still clearly discernible. In an analogous manner, individual, isolated facts of society together form the respective social and economic phenomena. Socio-economic statistics then pays attention and interprets not these many isolated facts but their participation in their specific spots in the corresponding phenomena of society.

To demonstrate this with an example, consider the social and economic phenomenon of "unemployment." There are all sorts of people who do not work who fall into various categories of "unemployment": lost a job but still looking; lost a job and gave up looking; just graduated from school searching for the first job; a PhD in Astrophysics, working at the check-out counter in a grocery store because no job is available in his specialty but continues to search for 'that' job; a retired worker occasionally working for extra cash. The possible list of persons not - or not really or fully - working is endless. None of these people individually are the socio-economic phenomenon of "unemployment." Together, however, they all form that phenomenon, giving it a particular shape: by region of the country where the persons without a job live, by type of industry where these persons last were employed, by kind of job in which they last worked, by their profession, race, age, gender, their levels of education, by their religion, etc. The uncertainties and statistical imprecisions of these individual, unemployed people determine that "lack of precision of that statistical socio-economic phenomenon called 'unemployment'."

I hope you got the 'picture.' Summarizing, many of the standard statistical features, like the Gauss curve, do not apply to data about society while important features of the socio-economic statistical data are absent and ignored by statistical theory. Standing out is the glaring omission of aggregation. Current statistical theory, particularly mathematical statistics, is oblivious of the important transformations taking place during the process of aggregation of data. These and other methods of socio-economic statistics are not dealt with in the standard statistical theory that grew out of, and is mostly oriented to, the problems of bio-statistics and biometry.

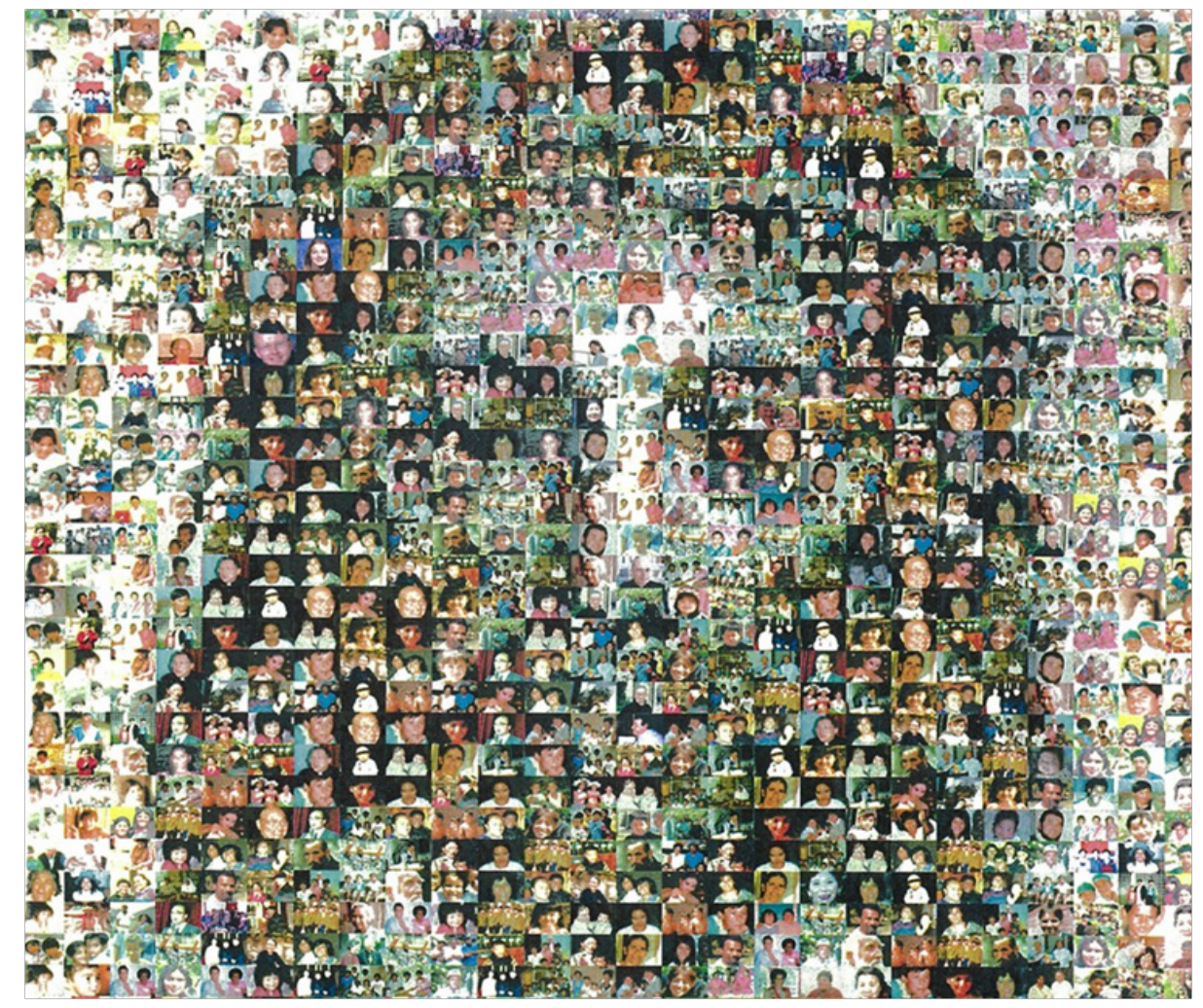

\section{Acknowledgement}

\section{None}

${ }^{2}$ The book "Interpreting Economic and Social Data - A Foundation of Descriptive Statistics" is listed on the web site of the Statistical Literacy Project $<$ http://Statlit.org $>$ To access the eight book reviews left click on 'Authors-Academic' then click on 'Winkler' above the yellow book, then click

\section{Conflict of interest}

\section{None}

on the name of each reviewer. The first reviewer's opinion starts: "Opening this book by Othmar Winkler is like splashing oneself with cold water at 5:30 in the morning. It's a wakeup call! The author lays out his "call to arms" in the preface." 